\title{
Modeling Spatial Characteristics in the Biological Control of Fungi at Leaf Scale: Competitive Substrate Colonization by Botrytis cinerea and the Saprophytic Antagonist Ulocladium atrum
}

\author{
G. J. T. Kessel, J. Köhl, J. A. Powell, R. Rabbinge, and W. van der Werf
}

First and second authors: Plant Research International, P.O. Box 16, 6700 AA, Wageningen, The Netherlands; third author: Department of Mathematics and Statistics, Utah State University, Logan 84322; fourth author: Wageningen University, Department of Plant Sciences, Group Plant Production Systems, P.O. Box 430, 6700 AK, Wageningen, The Netherlands; and fifth author: Wageningen University, Department of Plant Sciences, Group Crop \& Weed Ecology, P.O. Box 430, 6700 AK, Wageningen, The Netherlands. Accepted for publication 12 December 2004.

\begin{abstract}
Kessel, G. J. T., Köhl, J., Powell, J. A., Rabbinge, R., and van der Werf, W. 2005. Modeling spatial characteristics in the biological control of fungi at leaf scale: Competitive substrate colonization by Botrytis cinerea and the saprophytic antagonist Ulocladium atrum. Phytopathology 95:439-448.

A spatially explicit model describing saprophytic colonization of dead cyclamen leaf tissue by the plant-pathogenic fungus Botrytis cinerea and the saprophytic fungal antagonist Ulocladium atrum was constructed. Both fungi explore the leaf and utilize the resources it provides. Leaf tissue is represented by a two-dimensional grid of square grid cells. Fungal competition within grid cells is modeled using Lotka-Volterra equations. Spatial expansion into neighboring grid cells is assumed pro-

portional to the mycelial density gradient between donor and receptor cell. Established fungal biomass is immobile. Radial growth rates of $B$. cinerea and $U$. atrum in dead cyclamen leaf tissue were measured to determine parameters describing the spatial dynamics of the fungi. At temperatures from 5 to $25^{\circ} \mathrm{C}, \mathrm{B}$. cinerea colonies expanded twice as rapidly as $U$. atrum colonies. In practical biological control, the slower colonization of space by $U$. atrum thus needs to be compensated by a sufficiently dense and even distribution of conidia on the leaf. Simulation results confirm the importance of spatial expansion to the outcome of the competitive interaction between $B$. cinerea and $U$. atrum at leaf scale. A sensitivity analysis further emphasized the importance of a uniform high density cover of vital $U$. atrum conidia on target leaves.
\end{abstract}

Necrotrophic fungi of the genus Botrytis cause economically important diseases in many greenhouse and field crops $(11,12)$. Recently, it has been established that the saprophytic fungal antagonist Ulocladium atrum Preuss isolate 385 holds promise as an effective biological control agent against Botrytis spp. $(14,18$, 23,31). The biocontrol effect of $U$. atrum against Botrytis spp. is based on preemptive competitive colonization of dead plant tissue. Competition between both fungal species affects colonization as well as sporulation of Botrytis spp. (15). Suppression of sporulation of Botrytis spp. due to application of $U$. atrum has been observed in several Botrytis spp.-host combinations $(1,7,19,23,24)$. Reduction of sporulation has the potential to slow down, delay, and even prevent epidemics of Botrytis spp. (22). In cyclamen (Cyclamen persicum), saprophytic colonization of dead tissue by $B$. cinerea is an essential step toward mycelial infection of healthy plant parts. Colonization of necrotic tissue by $U$. atrum excludes $B$. cinerea and blocks this infection pathway (14). Repeated applications of $U$. atrum conidial suspensions to commercial cyclamen crops proved equally effective against $B$. cinerea as fungicide applications (18).

Systems analysis and dynamic simulation models are useful tools to explore biological control strategies (28) and have been applied successfully in assessing the potential of microbial biocontrol agents $(10,16)$. In this paper, a model is developed, taking account of temporal and spatial processes related to saprophytical colonization of dead cyclamen leaves by B. cinerea and $U$. atrum. Incorporation of spatial phenomena, such as fungal colonization

Corresponding author: G. J. T. Kessel; E-mail address: Geert.Kessel@wur.nl

DOI: 10.1094/PHYTO-95-0439

() 2005 The American Phytopathological Society of a leaf from a single starting point, into simulation models may yield relevant insights in the biological control abilities and requirements of $U$. atrum that differ from insights provided by models in which spatial aspects are not represented (15). Such insights can guide selection of potential antagonists, target diseases, and suggest application strategies.

The model developed in this paper simulates the spatiotemporal colonization of necrotic leaf tissue by $B$. cinerea and $U$. atrum as influenced by the density and distribution of conidia on the leaf and the presence of competing mycelium (colonies) in the leaf. The model integrates state of the art knowledge on the $B$. cinerea$U$. atrum interaction in dead cyclamen leaves $(13-15,17,21)$. Model results are compared with experimental results and a sensitivity analysis of the model is presented.

\section{MATERIALS AND METHODS}

Model concepts and implementation. The biological system. The model describes fungal growth and competitive phenomena in a dead cyclamen leaf, hereafter referred to as substrate, which is saprophytically colonized by $U$. atrum and B. cinerea. Fungal colonies originate from conidia, which in the case of $U$. atrum are introduced through spray applications, whereas the conidia of the pathogen result from natural spore production and dispersal. Conidia germinate and establish a mycelial microcolony or die. Mycelia grow through extension and branching of hyphae which explore the available leaf tissue and utilize the nutrients it contains (29). Established colonies expand radially and merge at contact if they are of the same species. Contact between colonies of $B$. cinerea and $U$. atrum results in arrestment of further spatial expansion in the case of $B$. cinerea, whereas $U$. atrum is capable of low level of co-colonization of the $B$. cinerea colony $(14,15)$. 
Interaction between the mycelia of Botrytis spp. and $U$. atrum affects the growth rate of the mycelia through nutrient competition $(14,15,17)$ but it does not result in any negative effect on existing biomass. Both fungi colonize dead leaf tissue and compete for a shared and limiting amount of primary resources $(14,15)$. Depletion of the resources stops mycelial growth. Secondary resources, i.e., resources left over by a preceding colonizer (2), are not utilized by $B$. cinerea and are used only to a limited extent by $U$. atrum, but this has no known effect on the pathogen (15). Sporulation develops from established mycelia.

Model structure. Processes are modeled at the scale of a leaf. To enable computation, space is subdivided into a two-dimensional grid of square grid cells. Grid cells are the smallest spatial units and state variables are assumed to be uniformly distributed within grid cells. State variables are conidial densities of $B$. cinerea and $U$. atrum on the leaf and mycelial densities of both fungi within the leaf. Conidia germinate on the leaf and give rise to an initial amount of mycelial biomass in the leaf as soon as germination is complete. Mycelium in the leaf grows within grid cells and extends from one grid cell into potentially four adjacent grid cells in a cross-shaped pattern. Growth of biomass is limited by the availability of the shared resource. Resource differentiation between both fungi, as reported by Kessel et al. (15), is not taken into account because secondary resource capture by $U$. atrum has no known negative short-term effect on $B$. cinerea. Reallocation of mycelial resources from the mycelium to the conidia, as suggested by Kessel et al. (15), is not included in the model.

The basic assumptions of the model are as follows. (i) Resource uptake by the mycelium is local within the grid cell and is used for growth. (ii) Resource availability throughout the substrate is constant. (iii) Maintenance respiration is negligible. (iv) The rate of resource uptake is proportional to the mycelial density increase rate in a cell and independent of mycelial age. (v) Resource competition is the only mode of interaction between fungal species. (vi) Fungal mycelia do not die during the simulation period.

Space. A dead cyclamen leaf was represented by a leaf-shaped grid consisting of square grid cells of 0.5 by $0.5 \mathrm{~mm}$. Grid cell size matches the scale at which mycelial density and conidial density were determined experimentally $(0.7$ by $0.7 \mathrm{~mm}$ for mycelial density and 0.5 by $0.5 \mathrm{~mm}$ for conidial density). Furthermore, grid cell length had to be at least as large as the distance covered by the fastest expanding fungus in one time step

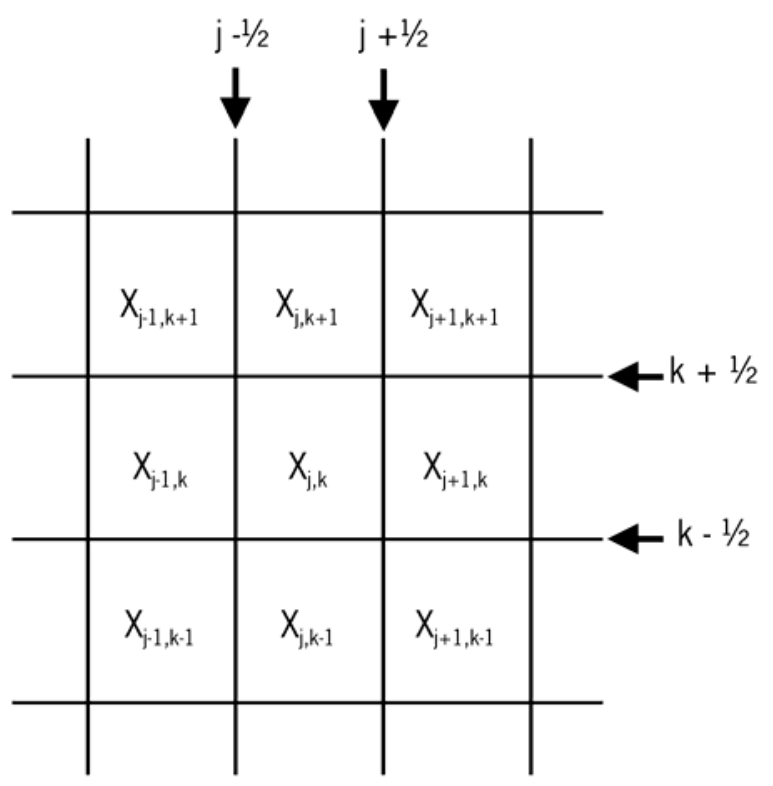

Fig. 1. Schematic representation of a grid representing variable $X$ and the index system used to designate grid cells and borders between grid cells. $\left(0.004 \mathrm{~mm} / \mathrm{min}\right.$ for $B$. cinerea at $\left.24^{\circ} \mathrm{C}\right)$. Simulations were done with whole leaves $\left(11.5 \mathrm{~cm}^{2}\right)$ or half leaves $\left(6.1 \mathrm{~cm}^{2}\right)$. The model was implemented using PCRaster, a geographic information system (GIS)-based software package which allows dynamic modeling in a spatially variable environment (Department of Physical Geography, Utrecht University, the Netherlands). In PCRaster, a stack of PCRaster maps (grids) represents the dead leaf, including a single map for each state variable. There are no fluxes of biomass or resources across the edges of the leaf.

Germination of conidia. Germination of conidia on the leaf was simulated by a distributed delay model: the fixed boxcar train (9). The boxcar train keeps track of all successive development stages of conidia during the germination process. Average germination times of $B$. cinerea and $U$. atrum conidia were 6.6 and $5.2 \mathrm{~h}$, respectively, at $18^{\circ} \mathrm{C}$. Variation in development time among individual spores, $26 \%$ for B. cinerea (37) and $22 \%$ for U. atrum (20), was implemented using boxcar trains with 15 and 21 boxcars, respectively.

Growth of fungal biomass. The mycelial biomass in grid cells increases through a combination of growth of biomass already present in the grid cell (local growth) and invasive contributions (spatial expansion) from neighboring grid cells. Growth is assumed to be limited by the availability of nutrients. Nutrient availability is assumed to be constant throughout the substratum, but nutrients are not explicitly present in the model.

Instead, local growth was simulated using a logistic growth model in which resource capture is made implicit in the state variables representing the biomass of the competitors. This choice was made to maximize parsimony, but without sacrificing realism.

Logistic growth equations are implemented as follows. Cell $(j, k)$ is the grid cell designated by integer index values $j$ and $k$ (Fig. 1). Let $B_{j, k, t}$ be the mycelial density of $B$. cinerea of cell $(j, k)$ at time $t$. $U_{j, k, t}$ represents the $U$. atrum mycelial density of cell $(j, k)$ at time $t$. The mycelial growth rate for $B$. cinerea and $U$. atrum due to local growth and not considering competition is then given by

$$
\begin{gathered}
\Delta B_{j, k}=r_{b} B_{j, k}\left(1-\frac{B_{j, k}}{K_{b}}\right) \Delta t \\
\Delta U_{j, k}=r_{u} U_{j, k}\left(1-\frac{U_{j, k}}{K_{u}}\right) \Delta t
\end{gathered}
$$

Here, $B_{j, k}$ is the mycelial density of Botrytis in grid cell $(j, k)$, a measure for biomass, expressed as a fraction of leaf volume because this is the way in which the occupancy of dead leaf tissue was quantified in experiments $(13,15)$. Likewise, the maximum colonization level $\left(K_{b}\right)$ is expressed as a volume fraction. $r_{b}$ is the local relative growth rate of Botrytis $\left(\right.$ time $\left.^{-1}\right)$.

Spatial expansion occurs in the $x$ and $y$ direction through each of the four boundaries of a grid cell (Fig. 1). The mycelial flux $(F)$ from grid cell $(j, k)$ to grid cell $(j+1, k)$ through boundary $j+$ $1 / 2$ (Fig. 1) is assumed to be proportional to the mycelial density gradient between the grid cells. For $B$. cinerea, this results in

$$
F b_{j+1 / 2}=-S_{b} \frac{B_{j+1, k}-B_{j, k}}{\Delta x} \Phi b_{j+1 / 2}
$$

$S_{b}$ is a spatial expansion coefficient and $\Delta x$ is the grid cell width. Equation 3 resembles Fick's law for diffusive flux. Fungal mycelium is however immobile. Mycelium grows into neighboring grid cells through hyphal elongation without biomass being removed from the donor grid cell. Therefore, inflow of biomass in a receptor grid cell does not result in outflow of biomass from the donor grid cell. Consequently, only influx of biomass has to be considered. A flux limiter, $\Phi b_{j+1 / 2}$ with values of either 0 or 1 , is used to prevent outflux but allow influx. The flux limiter functions as a switch. It is also used to prevent spatial expansion of biomass from grid cells with a biomass density too low for spatial 
expansion. This mycelial density threshold for spatial expansion is implemented as a fraction $T_{b}$ of the maximum colonization level $K_{b}$.

For $B$. cinerea, the flux limiter regulating influx into grid cell $(j, k)$ is defined as

$$
\begin{gathered}
\Phi b_{j+1 / 2}=\quad 0, B_{j+1, k}<B_{j, k} \\
0, B_{j+1, k}<T_{b} K_{b} \\
1, \text { otherwise }
\end{gathered}
$$

Analogous equations and flux limiters were used for mycelial fluxes through the other three boundaries. The total $B$. cinerea mycelial influx potential into grid cell $(j, k)$ then equals the sum of the four influxes:

$$
\begin{aligned}
& \frac{1}{\Delta t}\left(B_{j, k, t+1}-B_{j, k, t}\right)= \\
& \frac{-1}{\Delta x}\left(F b_{j+1 / 2, k, t}-F b_{j-1 / 2, k, t}\right)+\frac{-1}{\Delta y}\left(F b_{j, k+1 / 2, t}-F b_{j, k-1 / 2, t}\right)
\end{aligned}
$$

Combining equation 3 and analogous equations for $B$. cinerea mycelial influx potential and equation 5 and taking into account that $\Delta y=\Delta x$ results in the total influx potential of $B$. cinerea into grid cell $(j, k)$ :

$$
\begin{aligned}
& B_{j, k, t+1}-B_{j, k, t}= \\
& S_{b} \frac{\Delta t}{\Delta x^{2}}\left[\begin{array}{l}
\Phi b_{j+1 / 2}\left(B_{j+1, k, t}-B_{j, k, t}\right)+\Phi b_{j-1 / 2}\left(B_{j-1, k, t}-B_{j, k, t}\right)+ \\
\Phi b_{k+1 / 2}\left(B_{j, k+1, t}-B_{j, k, t}\right)+\Phi b_{k-1 / 2}\left(B_{j, k-1, t}-B_{j, k, t}\right)
\end{array}\right]
\end{aligned}
$$

An analogous set of equations was developed for $U$. atrum.

Competition for resources is assumed to take place within grid cells and is modeled using an approach previously used by Lotka (26), Volterra (34), and Zegerman et al. (38). As implemented here, both species experience interspecific competition in exactly the same way as intraspecific competition through the depletion of a single shared resource by both species. The competitive effect of both species is expressed in a competition coefficient $\alpha$ which reflects the resource use efficiency. $\alpha$ is indexed as $\alpha_{u b}$ to characterize the effect of $U$. atrum on $B$. cinerea and vice versa for $\alpha_{b u}$. The first of these coefficients is calculated as $K_{u} / K_{b}$ while the other is calculated as $K_{b} / K_{u}$ (Table 1 ).

Overall, the potential for increase of the $B$. cinerea mycelial density in grid cell $(j, k)$ is given by the potential for local growth plus the potential invasive contributions. Both potentials for growth are however limited by the resources available within the grid cell $(j, k)$. Thus, equation 1 for local growth and equation 6 for the total invasive potential can be combined into an equation describing the $B$. cinerea mycelial density increase in grid cell $(j, k)$ accounting for local growth, mycelial influx, and resource limitation:

$$
B_{j, k, t+1}=\left(r_{b} B_{j, k}+\text { invasive potential B. cinerea }\right)\left(1-\frac{B_{j, k}+\alpha_{b u} U_{j, k}}{K_{b}}\right)
$$

An analogous equation was used for $U$. atrum:

$$
U_{j, k, t+1}=\left(r_{u} U_{j, k}+\text { invasive potential } U \text {.atrum }\right)\left(1-\frac{U_{j, k}+\alpha_{u b} B_{j, k}}{K_{u}}\right)
$$

Time step. The time step was based on the germination rate of $U$. atrum conidia, the fastest process included in the model. The average germination time of $U$. atrum conidia is $2.8 \mathrm{~h}$ at $30^{\circ} \mathrm{C}$, which is the optimal temperature (20). Implementation of the germination process in a fixed boxcar train of 21 boxcars leads to a residence time of 8 min per boxcar. Hence, a time step of $1 \mathrm{~min}$ was adopted to numerically simulate system behavior.

Model parameters. Table 1 lists all variables and parameters included in the model. Estimates for relative mycelial growth rates $\left(r_{b}\right.$ and $\left.r_{u}\right)$ and the initial mycelial density assigned to germinated conidia $\left(I_{b}\right.$ and $\left.I_{u}\right)$ were calculated from data presented by Kessel et al. (15). Straight lines were fitted to data describing the log-transformed mycelial colonization in time. Only data from the first $60 \mathrm{~h}$ of (near exponential) mycelial density increase were included. The relative growth rates $\left(r_{b}\right.$ and $\left.r_{u}\right)$ were estimated as the slope of the fitted lines at $18^{\circ} \mathrm{C}$. The initial mycelial density constituted by a germinated conidium $\left(I_{b}\right.$ and $I_{u}$ ) was estimated from the regression line by dividing the back-transformed total mycelial density generated after the average germination time (provided above) by the conidial density to yield $I_{b}$ and $I_{u}$.

The maximum colonization level for both fungi $\left(K_{b}\right.$ and $\left.K_{u}\right)$ was estimated as the average maximum colonization level given by Kessel et al. (15).

The spatial expansion thresholds $\left(T_{b}\right.$ and $\left.T_{u}\right)$ determine the shape of the mycelial fronts as they are seen in a radial cross section through the colony. Values close to zero result in a long tail of low mycelial density preceding the main body of the colony, whereas values close to one result in a steep mycelial front. Quantitative data to estimate the spatial expansion threshold were not available but histological observations invariably show a steep mycelial front for both $B$. cinerea and $U$. atrum. The mycelial density at the edge of the colony declines from the maximum colonization level within the colony to zero outside the colony within a range of 0.5 to $2 \mathrm{~mm}$. The spatial expansion thresholds $\left(T_{b}\right.$ and $T_{u}$ ) were set to 0.85 to match these histological observations.

Experiment 1. Spatial expansion coefficients $S_{b}$ and $S_{u}$ as influenced by temperature were determined following single species point inoculation of sterile dead cyclamen leaves. Leaf tips were point-inoculated using a sterile glass stamp (15) and incubated in the dark at constant temperatures: 5, 12, 18, 24, and $30^{\circ} \mathrm{C}$ for $B$. cinerea and $5,12,18,24,28$, and $33^{\circ} \mathrm{C}$ for $U$. atrum. Seven replicate petri dishes with two leaves each were included for each species $\times$ temperature combination. Two replicate experiments were carried out. Successful inoculations resulted in clearly visible, brown, radially growing colonies for both fungi. Histological observations confirmed that the brown area corresponded

\begin{tabular}{|c|c|c|c|}
\hline & Symbol & Estimate & Unit \\
\hline \multicolumn{4}{|l|}{ Variables } \\
\hline Conidial density & $\begin{array}{l}B_{c o n} \\
U_{c o n}\end{array}$ & $\ldots$ & Conidia $\mathrm{mm}^{-2}$ \\
\hline Mycelial density & $B, U$ & $\ldots$ & $\begin{array}{l}\text { Mycelial volume frac- } \\
\text { tion in grid cell (-) }\end{array}$ \\
\hline \multicolumn{4}{|l|}{ Establishment parameters } \\
\hline Germination rate & $\begin{array}{l}V_{b} \\
V_{u}\end{array}$ & $\begin{array}{l}0.0025 \\
0.0033\end{array}$ & $\min ^{-1}$ \\
\hline $\begin{array}{l}\text { Initial mycelial density of a } \\
\text { germinated conidium }\end{array}$ & $\begin{array}{l}I_{b} \\
I_{u}\end{array}$ & $\begin{array}{l}0.000018 \\
0.000042\end{array}$ & $\begin{array}{l}\text { Mycelial volume frac- } \\
\text { tion in grid cell (-) }\end{array}$ \\
\hline \multicolumn{4}{|l|}{ Logistic growth parameters } \\
\hline Relative growth rate & $\begin{array}{l}r_{b} \\
r_{u}\end{array}$ & $\begin{array}{l}0.0012 \\
0.0010\end{array}$ & $\min ^{-1}$ \\
\hline Maximum colonization level & $\begin{array}{l}K_{b} \\
K_{u}\end{array}$ & $\begin{array}{l}0.05 \\
0.05\end{array}$ & $\begin{array}{l}\text { Mycelial volume frac- } \\
\text { tion in grid cell (-) }\end{array}$ \\
\hline \multicolumn{4}{|l|}{ Spatial parameters } \\
\hline Spatial expansion coefficient & $\begin{array}{l}S_{b} \\
S_{u}\end{array}$ & $\begin{array}{l}0.01398 \\
0.00459\end{array}$ & $\mathrm{~mm}^{2} \min ^{-1}$ \\
\hline Spatial expansion threshold & $\begin{array}{l}T_{b} \\
T_{u}\end{array}$ & $\begin{array}{l}0.85 \\
0.85\end{array}$ & $\begin{array}{l}\text { Mycelial volume frac- } \\
\text { tion in grid cell (-) }\end{array}$ \\
\hline
\end{tabular}
to internally colonized leaf tissue. The distance traveled by the front of the colony was measured daily along a marked transect with a ruler.

The radial growth rate was calculated as the slope of the linear regression line of measured colony radius ( $y$ axis) on time ( $x$ axis). To characterize the temperature response of radial growth

TABLE 1. Variables, parameters, and their estimates at $18^{\circ} \mathrm{C}$ included in the simulation model 
rate, Logan curves (25) were used. Logan curves are used widely in insect biology to describe temperature-dependent rate phenomena and have the following form:

$$
Y_{T}=\psi\left(e^{\rho\left(T-T_{b}\right)}-e^{\rho\left(T_{M}-T_{b}\right)-\frac{\left(T_{M}-T\right)}{\Delta T}}\right)
$$

These curves generally describe an asymmetric sigmoid increase of the response variable growth rate $\left(Y_{T}\right)$ with temperature to an optimum temperature, after which the growth rate quickly decreases to zero at the maximum temperature $\left(T_{M}\right)$. The base temperature $T_{b}$ was set to $5^{\circ} \mathrm{C}$ for both fungi. The other parameters were determined by nonlinear least squares regression using Genstat 5 (Numerical Algorithms Group Inc., Oxford, UK). The parameters are interpreted as follows: $\psi$ is approximately equal to the radial growth rate at the base temperature, $\rho$ characterizes the curvature of the increase of $Y_{T}$ toward the optimum temperature, and $\Delta T$ represents the temperature range over which $Y_{T}$ declines from the maximum at the optimum temperature to zero at the maximum temperature.

Validation of spatial aspects. Experiment 2. Colonies of $B$. cinerea and $U$. atrum were started in different spatial arrangements on dead, sterile, half cyclamen leaves. Leaves were pointinoculated with conidia (15) in 1 of 12 different inoculation patterns (Fig. 2). The leaves were incubated in the dark at $18^{\circ} \mathrm{C}$. Inoculations resulted in $66 \pm 43$ and $127 \pm 80$ conidia per inoculation point for $B$. cinerea and $U$. atrum, respectively. The standard deviations given are the population parameters describing the variability among different inoculation points. Four replicate leaves were inoculated for each inoculation pattern. After 2 weeks incubation, the number of successful inoculations was determined and the sporulation patterns developed on the leaves were examined with a dissecting microscope at a magnification of $\times 100$. The fraction of leaf area covered by each species was estimated and sporulation patterns were reproduced in a drawing of each leaf in a 1:1 reproduction.

Following the experiment, simulations were initialized with the same inoculation patterns as used in the experiments. For the simulated inoculation, all conidia per inoculation point were deposited in a single 0.5 by $0.5 \mathrm{~mm}^{2}$ grid cell. The number of conidia per simulated inoculation point was randomly drawn from a log-normal distribution and rounded to the nearest integer. Parameters for the log-normal distributions corresponded to the average and standard deviation of the logarithm of the number of conidia per inoculation point in the experiment (27). Simulations for each of four replicate leaves were included. Simulation time was 2 weeks for each run when a stable final result was reached in all simulations.

Validation of temporal aspects. Single species dynamics and competition after simultaneous spray inoculation. Experimental and simulated results on single species dynamics and competition between $B$. cinerea and $U$. atrum were compared. Kessel et al. (15) describe a series of experiments in which the internal colonization of dead cyclamen leaf is followed through time, using immuno-histological techniques (13). The last of these experiments (Fig. 2D in literature citation 15) was used for model validation. Conidia of $B$. cinerea and $U$. atrum were spray-inoculated on sterile dead cyclamen leaves resulting in average conidial densities of $25 \pm 6 \mathrm{~mm}^{-2}$ for $B$. cinerea and $35 \pm 5 \mathrm{~mm}^{-2}$ for $U$. atrum as determined by microscopical observation. The standard deviations given are the population parameters describing the variability among different $1 \mathrm{~mm}^{2}$ areas. Three types of inoculations were included: B. cinerea alone, $U$. atrum alone, and $B$. cinerea and $U$. atrum together. The internal mycelial colonization level was determined at regular intervals throughout incubation. Five replicate leaves were included for each combination of treatment and sampling time. Further details are given by Kessel et al. (15).
In the simulations, conidial densities per grid cell were randomly drawn from a log-normal distribution and rounded to the nearest integer. Parameters of the log-normal distribution corresponded to the average and standard deviation of the logarithm of the conidial density per grid cell in the experiment mentioned previously. As in the experiment, five replicate leaves were included in the simulation. Simulation time was 2 weeks for each run. Average colonization levels were calculated per leaf after each time step.

Two species dynamics with varying application intervals. The second experiment used for validating temporal aspects of model performance was the "head start experiment" described by Kessel et al. (15). This experiment aimed at measuring the effect of differences in the relative time of inoculation of $B$. cinerea and $U$. atrum on the final sporulation by both species on sterile dead cyclamen leaves. Conidial densities were $46 \pm$ $16 \mathrm{~mm}^{-2}$ for $B$. cinerea and $45 \pm 9 \mathrm{~mm}^{-2}$ for $U$. atrum. The standard deviations given are the population parameters describing the variability among different $1 \mathrm{~mm}^{2}$ areas. Application intervals between both inoculants created competitive advantages for one or the other species. Sporulation intensity was assessed after 2 weeks incubation at $18^{\circ} \mathrm{C}$. Analysis focused on the relative spore yields, in a fashion similar to the way De Wit (3) analyzed experiments on plant competition with replacement series looking at seed yields of cereal species. Details are given by Kessel et al. (15).

Simulations were carried out using identical initial conditions (variable conidial densities, 10 application intervals), temperature and growing period ( 2 weeks) as in the experiment. A difference between experiment and simulation in this case is that the experimental data are based on sporulation intensities, whereas simulation results are based on mycelial densities.

Sensitivity analysis. A sensitivity analysis was performed by changing parameter values (Table 1 ) with +20 or $-20 \%$ except in the case of the spatial expansion thresholds $\left(T_{b}\right.$ and $\left.T_{u}\right)$, which were modified with +5 or $-5 \%$. The relative sensitivity of the output variable to these perturbations was calculated as $(\Delta Z / Z) /$ $(\Delta Y / Y)$, where $Z$ is the relevant output variable and $Y$ is the parameter (30).

Two initial situations were distinguished: point inoculations and homogeneous (spray) inoculations. Mono- and mixed cultures of $B$. cinerea and $U$. atrum were considered for both inoculation methods. The sensitivity analysis therefore comes in four parts.

PCRaster maps representing whole cyclamen leaves were used in the simulations. Patterns 1 and 11 (Fig. 2) were used for simulated point inoculations. To determine sensitivity to changes in establishment parameters (Table 1), simulation runs were initialized with an equal number of 10 established conidia per inoculation point for each species. To determine sensitivity to changes in logistic growth parameters (Table 1), simulation runs were initialized with inoculation points filled up to the maximum colonization level. Spray inoculations were implemented by depositing 10 conidia in each grid cell (equivalent to 40 conidia $\mathrm{mm}^{-2}$ ).

For each of the four parts of the sensitivity analysis, a relevant output variable was selected. For single species point inoculations, the output parameter was the colony surface area following 7 days of incubation, just before the fastest growing colony reached the edge of the leaf. For two species point inoculations, the output variable was the surface area covered by $B$. cinerea and $U$. atrum after 2 weeks simulation. Any area co-colonized by $B$. cinerea and $U$. atrum was divided evenly between the species. For single species homogeneous inoculations, the average colonization level after $100 \mathrm{~h}$ was used as output variable. For two species homogeneous inoculations, the final result, represented by the average colonization level after 2 weeks simulation time, was used as output variable. 


\section{RESULTS}

Parameterization of the spatial expansion of $B$. cinerea and $\boldsymbol{U}$. atrum. The radius of the fungal colonies in experiment 1 increased linearly with time. The measured response of radial growth rate of $B$. cinerea and $U$. atrum colonies, growing in sterile dead cyclamen leaves in experiment 1 , to temperature was well described by the fitted Logan curves (Fig. 3). The variance accounted for was 99.6 and $93.1 \%$ for B. cinerea and U. atrum, respectively. Parameter estimates (with standard error in paren-
Inoculation pattern

Experimental result

Simulated result

Inoculation pattern

Experimental result

Simulated result
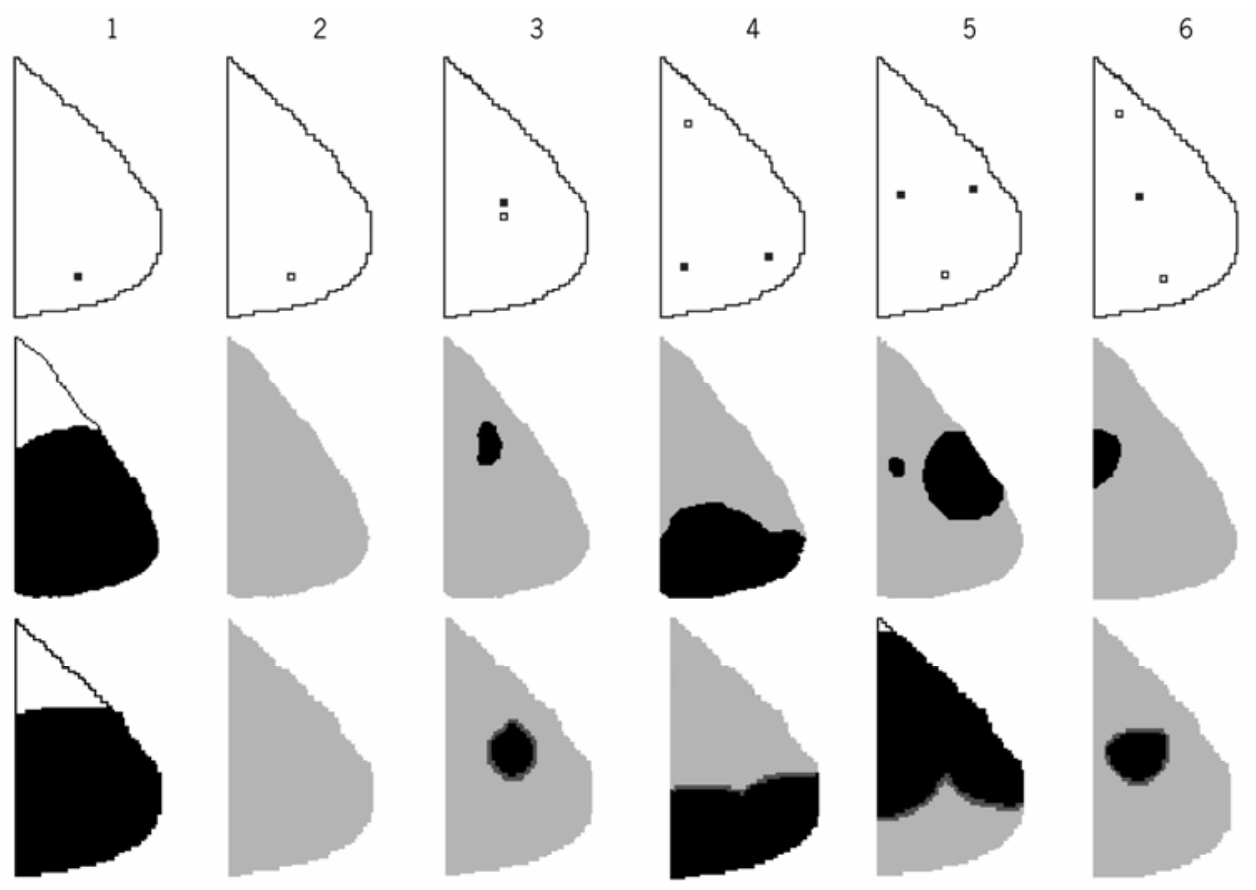

7
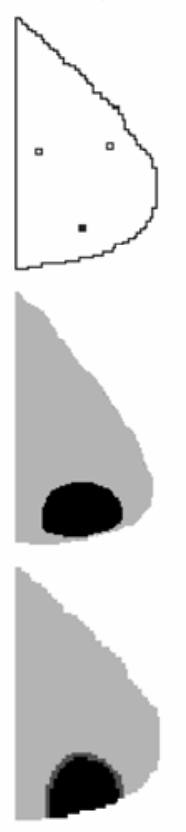

8
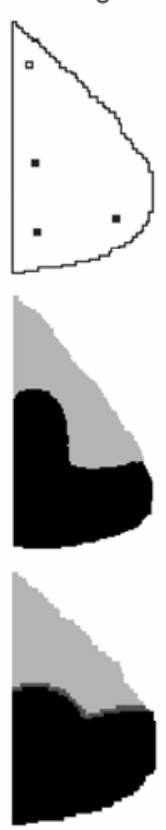

9
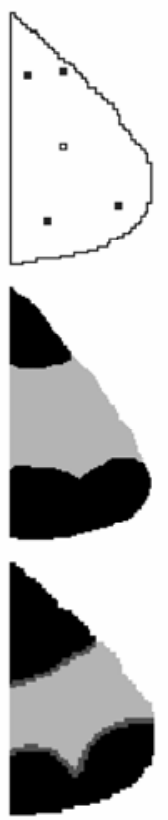

10
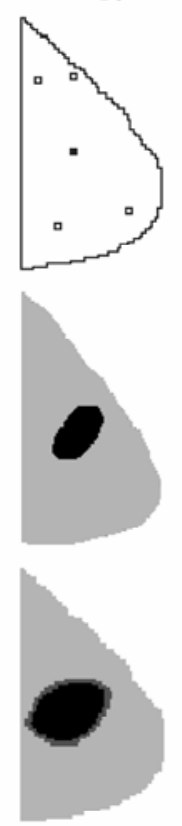

11
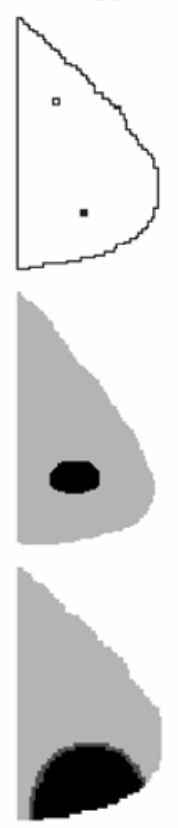
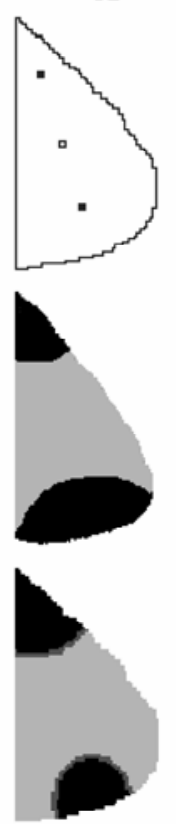

\footnotetext{
- Inoculation point B. cinerea.

- Inoculation point U. atrum.
}

Light gray: Experimental: leaf area sporulation with $B$. cinerea only. Simulated: leaf area colonized by $B$. cinerea mycelium only.

Black: $\quad$ Experimental: leaf area sporulation with $U$. atrum only. Simulated: leaf area colonized by $U$. atrum mycelium only.

Dark gray Simulated leaf area with mycelial colonization of both $B$. cinerea and $U$. atrum.

White Uncolonized leaf area.

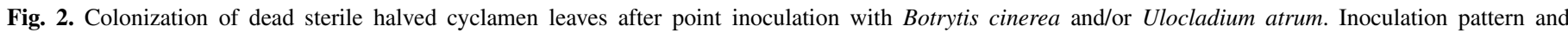
experimental and simulated results after 2 weeks incubation at $18^{\circ} \mathrm{C}$. Depicted leaves were randomly selected from four replicate leaves. 
theses) for the Logan curves were as follows: $\psi=1.85(0.31) \mathrm{mm}$ day $^{-1}, \rho=0.12(0.01)^{\circ} \mathrm{C}^{-1}, T_{M}=30.0(0.03)^{\circ} \mathrm{C}, \Delta T=5.3(0.5)^{\circ} \mathrm{C}$, and $T_{b}=5^{\circ} \mathrm{C}$ for $B$. cinerea; and $\psi=0.67(0.20) \mathrm{mm} \mathrm{day}^{-1}, \rho=$ $0.07(0.03)^{\circ} \mathrm{C}^{-1}, T_{M}=33.5(0.04)^{\circ} \mathrm{C}, \Delta T=2.8(2.5)^{\circ} \mathrm{C}$, and $T_{b}=$ $5^{\circ} \mathrm{C}$ for $U$. atrum. The radial growth rate at $18^{\circ} \mathrm{C}$ was calculated to be $4.9 \mathrm{~mm} \mathrm{day}^{-1}$ for $B$. cinerea and $1.7 \mathrm{~mm}^{-1} \mathrm{day}^{-1}$ for $U$. atrum. The spatial expansion coefficients $S_{b}$ and $S_{u}$ were calibrated to 0.01398 and $0.00459 \mathrm{~mm}^{2} \mathrm{~min}^{-1}$ at $18^{\circ} \mathrm{C}$ for $B$. cinerea and $U$. atrum, respectively.

General behavior of the model. Point inoculations resulted in circular colonies, radially growing at a constant growth rate. Mycelial densities in the colony reached the maximum colonization level in the center with a steep mycelial front at the edges of the colony. There were narrow zones of overlap between colonies of both species (Fig. 2).

Validation of spatial aspects. Simulated and experimental results from experiment 2 are given in Figure 2 for one randomly chosen replicate leaf for each experimental and simulated inoculation pattern. In general, the simulated and experimental colonization patterns are very similar, indicating that the main aspects of spatial colonization and competition are well captured by the model.

An interesting case was presented by inoculation pattern 5 . This pattern produced highly variable results in experiments and simulations. When $U$. atrum established quickly and closed the gap between both inoculation points, $B$. cinerea was excluded from the top part of the leaf resulting in a colonization pattern resembling the simulated pattern. When $U$. atrum did not close the gap in time, $B$. cinerea was given access to the top part of the leaf, resulting in a colonization pattern resembling the experimental pattern given in Figure 2.

Quantitatively, $71.3 \%$ of the leaf was colonized by B. cinerea in experiment 2 averaged over all 12 inoculation patterns, whereas an average of $61.2 \%$ colonization was reached in the simulations. $U$. atrum colonized 21.6 and $34.5 \%$ of the leaf area in the experiment and simulations, respectively. The simulations thus somewhat overestimated the area covered by $U$. atrum while they underestimated the area covered by $B$. cinerea. This difference is largely due to an overestimation of the establishment of $U$. atrum colonies in the simulations. Experimentally, $78 \%$ of the $U$. atrum inoculations were successful, whereas $B$. cinerea inoculations were $100 \%$ successful. Simulated inoculations were successful by default because establishment was not included in the model as a separate process.

Patterns 6, 7, 9, and 11 illustrate that the outcome of the fungal interaction was generally sensitive to the exact position of the

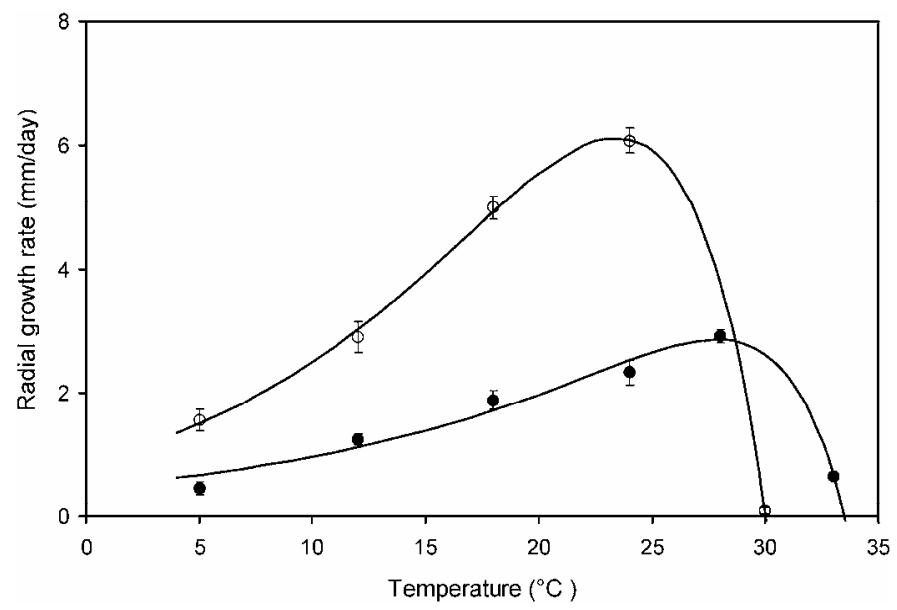

Fig. 3. Effect of temperature on the radial growth rate of Botrytis cinerea and Ulocladium atrum colonies growing in dead sterile cyclamen leaf tissue. Open marker $=$ B. cinerea . Solid marker $=U$. atrum . Solid lines $=$ Logan curves fitted to the experimental data. Error bars represent the standard error of the mean. inoculation points. For patterns 7 and 11, the simulated $U$. atrum colony extended to the edge of the leaf while in the experiment, $U$. atrum appeared as a sporulating island, entirely surrounded by B. cinerea. For pattern 6, a similar effect can be observed. Pattern 9 illustrates this sensitivity most clearly at the tip of the leaf.

For pattern $3, B$. cinerea and $U$. atrum were inoculated close to each other. This allows an interaction between fungi during the early phases of colonization in which either species is able to out compete the other and claim the vast majority of the substratum. Differences in density and quality of the initial inoculum most likely determine the outcome of such an early interaction.

Validation of temporal aspects. Single species dynamics and competition after simultaneous spray inoculation. Results of the experiment and simulation are given in Figure 4. The main characteristics of temporal mycelial density dynamics are captured by the model. The large variation within and between sampling times present in the experimental data is not reproduced by the model. Causes for the variability in the experimental observations are undetermined but possibly related to the local nutritional status of the substrate and/or fungal physiology.

Two species dynamics with varying application intervals. $\mathrm{Re}-$ sults from the experimental and simulated head start experiment
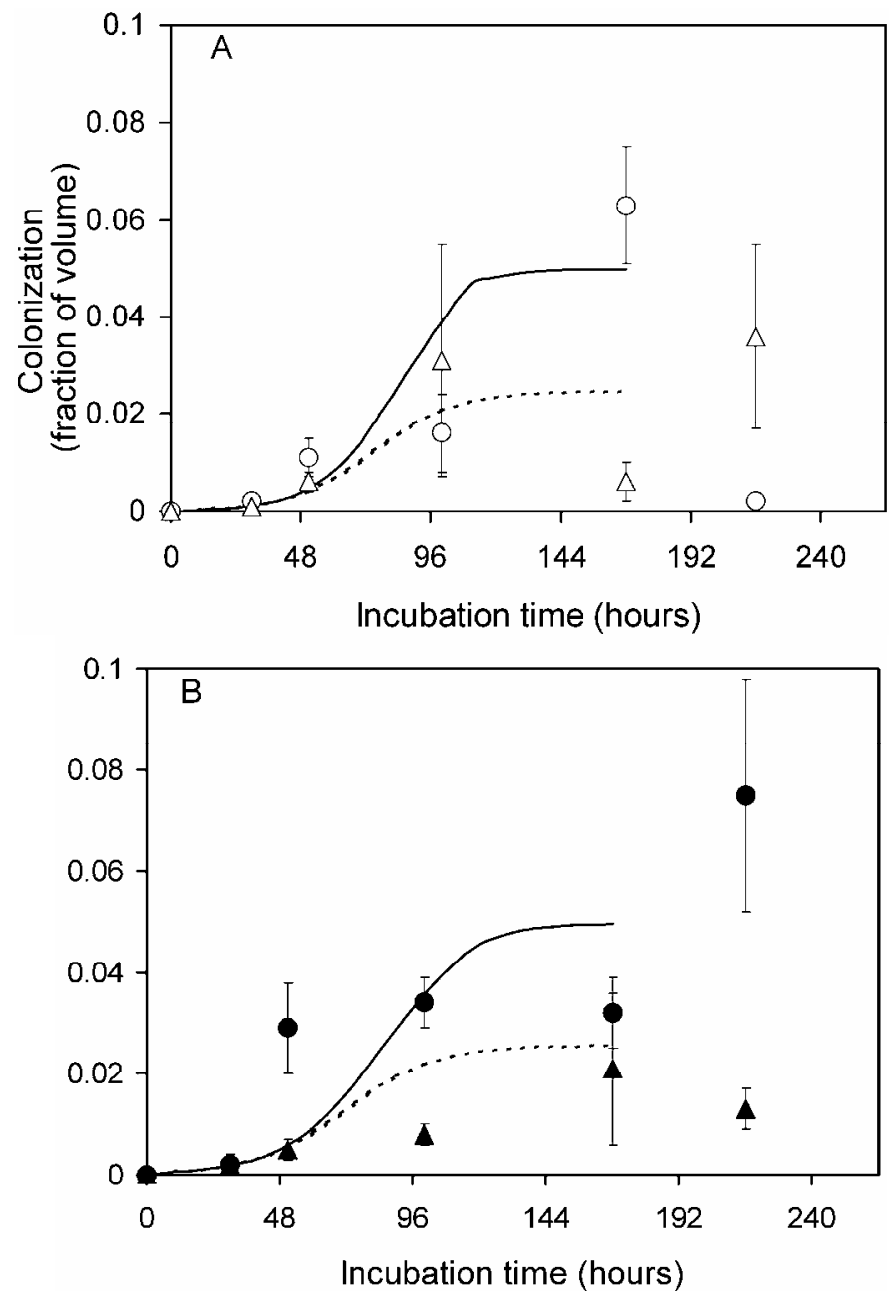

Fig. 4. Time course of colonization of sterile dead cyclamen leaf tissue by $\mathbf{A}$, Botrytis cinerea and $\mathbf{B}$, Ulocladium atrum after spray inoculation with conidial suspensions $\left(1 \times 10^{6}\right.$ conidia per $\left.\mathrm{ml}\right)$ of either or both fungi at time $=$ 0 . Experimental and simulated results. Open circle $=$ experimental $B$. cinerea monoculture. Solid circle $=$ experimental $U$. atrum monoculture. Open triangle $=$ experimental $B$. cinerea in mixed culture with $U$. atrum. Solid triangle $=$ experimental $U$. atrum in mixed culture with $B$. cinerea . Solid line $=$ Simulated result of the monoculture. Dashed line $=$ Simulated result of the mixed culture. Error bars represent the standard error of the experimental means of five replicate leaves. 
are given in Figure 5. The general shape of the experimental relative yield lines (RY, average yield in mixed culture divided by the average yield in the corresponding monoculture) was reproduced by the simulated RY lines. Quantitatively, the simulated RY lines for $B$. cinerea and $U$. atrum underestimate the yield of $B$. cinerea in the -24 to $+24 \mathrm{~h}$ application range. The $U$. atrum yield is also underestimated in the -12 to $+12 \mathrm{~h}$ application range. As a result, the simulated RY lines for $B$. cinerea and $U$. atrum were less steep than the experimental RY lines and the intersection of both simulated RY lines occurs at a lower RY than in the experiments. As a consequence, the simulated RY totals (RYT) line does not display the typical convex shape of the experimental RYT line, indicating that resource capture and depletion during competitive colonization is more complex than assumed in the model.

Sensitivity analysis. Single species dynamics following uniform inoculation. The average colonization level after $100 \mathrm{~h}$ simulated growth was sensitive to changes in the relative growth rate of both fungi, $r_{b}$ and $r_{u}$ (Table 2A). Furthermore, this average colonization level was sensitive to changes in the maximum colonization level $\left(K_{b}\right.$ and $\left.K_{u}\right)$ and to the establishment parameters $V$. and $I$.. The behavior of uniformly inoculated single species systems was insensitive to changes in parameters determining spatial expansion $S$. and $T$.

Two species dynamics following uniform inoculation. In general, the trends described for the uniformly inoculated monocultures remain valid for their mixed culture equivalent (Table 2B). The result of this competitive interaction is however more sensitive to changes in the establishment parameters $V$. and $I$. than in the single species situation above. This indicates that the early interaction (e.g., early resource depletion) is of key importance to the final outcome.

Single species dynamics following point inoculation. The colony surface area was sensitive to changes in the spatial expansion thresholds $(T$.$) and the spatial expansion coefficients (S$.) (Table $2 \mathrm{C}$ ). Changes in the establishment parameters ( $I$. and $V$.) and logistic growth parameters $\left(r_{b}, r_{u}\right)$ have a smaller, but still substantial, effect on the colony surface area. As determined with the current output variable, this system is insensitive to changes in the maximum colonization level $K_{b}$ or $K_{u}$.

Two species dynamics following point inoculation. The proportion of leaf area colonized by B. cinerea or $U$. atrum in mixed cultures responded in a manner similar to individual parameter changes as the individual colony size in single species simulations (Table 2D). The trends described for point-inoculated monocultures also apply to point-inoculated mixed cultures. U. atrum was found to be more sensitive to parameter changes than $B$. cinerea. This was especially true for changes in the expansion thresholds $T_{b}$ and $T_{u}$, possibly due to a lower radial growth rate of $U$. atrum compared with $B$. cinerea. This result clearly illustrates the importance of the ability to quickly capture space in a biocontrol situation where competitive success is required for survival of the species.

\section{DISCUSSION}

The purpose of the research presented in this paper was to integrate knowledge on temporal and spatial aspects of competitive substrate colonization by $B$. cinerea and $U$. atrum. A spatiotemporal simulation model was constructed and used to study system behavior. Results emphasize the importance of capturing space for the survival and reproduction of both pathogen and antagonist.

The integration level of the model presented here is suitable to study practical as well as more fundamental questions at leaf level. Models describing growth and morphogenesis at the level of individual hyphae $(4,5,32,35)$ are better suited to study more fundamental questions at the tissue level or lower. Models includ- ing less detail than the present model, e.g., describing fungal colonies as radially growing circles (33), cannot account for growing and competing mycelia within the same space and are therefore better suited to study problems at the plant level or higher.

Within the model, resource uptake is strictly local, initial resource availability is constant throughout the substrate, mycelial age does not influence resource uptake, maintenance respiration is absent, and mycelia do not die. These assumptions are-in the given order-increasingly at odds with biological reality. Experimental data have shown that mycelia do die and eventually dissolve $(14,36)$. Maintenance respiration may be negligible when compared with growth respiration but experimental data to check the credibility of this hypothesis are not available. Resource availability is unlikely to be constant within a dead leaf and between different dead leaves. Resource uptake is unlikely to be strictly local due to the nutrient transport capabilities of hyphae.

Fungal growth and competition of two strains of Fusarium have previously been described using a "Lotka-Volterra" competition approach (38) similar to the one used in this paper. To the best of our knowledge, this is the first time however that logistic growth of fungal biomass and Lotka-Volterra" competition have been combined in a spatially explicit model. Temporal aspects of substrate colonization were dominated by the relative growth rate of both fungi and the initial mycelial density per grid cell generated by germinating conidia (Table 2). Spatial expansion was modeled using a flux approach in which invasion of biomass was accounted for by not subtracting the "transported amount" from its source. Flux of biomass, normally resulting in dispersal of biomass over space, was thus turned into a spatial growth process describing the biology of fungal growth. Implementation of a flux limiter was necessary to prevent the artifact of numerical dispersion (8), which would have resulted in long tails of low mycelial density preceding the true mycelial front. The values assigned to the threshold values for spatial expansion were chosen to match histological observations on the shape of the mycelial front. In doing so, the flux limiter $\times$ spatial expansion threshold combina-

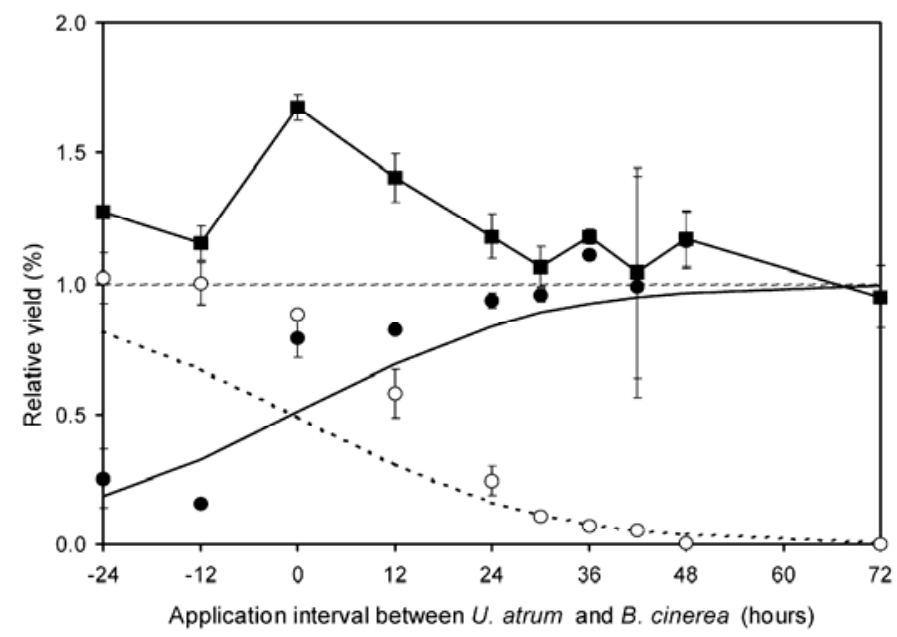

Fig. 5. Relative yields (RY, average yield in mixed culture divided by the average yield in the corresponding monoculture) and relative yield totals (RYT) of an experimental and simulated head start experiment. Sterile dead cyclamen leaf tissue was competitively colonized by Botrytis cinerea and Ulocladium atrum after spray inoculation with conidial suspensions $(1 \times$ $10^{6}$ conidia per $\mathrm{ml}$ ) of $B$. cinerea and $U$. atrum, $B$. cinerea and sterile tap water, or $U$. atrum and sterile tap water at different application intervals ranging from $24 \mathrm{~h}$ application advantage for $B$. cinerea $(-24 \mathrm{~h})$ to $72 \mathrm{~h}$ application advantage for $U$. atrum $(72 \mathrm{~h})$. Open circle $=B$. cinerea experimental RY. Solid circle $=U$. atrum experimental RY. Solid line and solid square marker $=$ experimental RYT. Solid line $=U$. atrum simulated RY. Dotted line $=B$. cinerea -simulated RY. Dashed line $=$ simulated RYT. Experimental RYs and RYT are based on sporulation. Simulated RYs and RYT are based on the mycelial colonization level of leaves. Error bars represent standard error of the mean. 
tion was turned into a biological parameter whose value was higher than the values commonly assigned to flux limiters to prevent unrealistic spatial expansion (typically 0.01 to 0.1 ). Spatial expansion was dominated by the value of the spatial expansion threshold although the model result was also sensitive to the spatial expansion coefficient (Table 2).

Comparison of simulated and experimental temporal trends of substrate colonization was complicated by large standard errors of

TABLE 2. Sensitivity analysis of the simulation model ${ }^{\mathrm{w}}$

\begin{tabular}{|c|c|c|c|c|c|c|}
\hline \multirow[b]{3}{*}{ Parameter } & \multirow[b]{3}{*}{ Reference value } & \multirow[b]{3}{*}{ Unit } & \multicolumn{4}{|c|}{ Relative sensitivity $^{\mathrm{x}}$} \\
\hline & & & \multicolumn{2}{|c|}{ Ulocladium atrum } & \multicolumn{2}{|c|}{ Botrytis cinerea } \\
\hline & & & + & - & + & - \\
\hline \multicolumn{7}{|c|}{$\begin{array}{l}\text { A. Single species dynamics following } \\
\text { uniform inoculation }\end{array}$} \\
\hline$V_{b}$ & 0.0025 & $\min ^{-1}$ & $\ldots$ & $\ldots$ & 0.09 & 0.14 \\
\hline$I_{b}$ & 0.000018 & {$[-]$} & $\ldots$ & $\ldots$ & 0.21 & 0.28 \\
\hline$r_{b}$ & 0.0012 & $\min ^{-1}$ & $\ldots$ & $\ldots$ & 1.08 & 2.03 \\
\hline$S_{b}$ & 0.01398 & $\mathrm{~mm}^{2} \min ^{-1}$ & $\ldots$ & $\ldots$ & 0.72 & 0.80 \\
\hline$K_{b}$ & 0.05 & {$[-]$} & $\ldots$ & $\ldots$ & 0.00 & 0.00 \\
\hline$T_{b}$ & 0.85 & {$[-]$} & $\ldots$ & $\ldots$ & 0.00 & 0.00 \\
\hline$V_{u}$ & 0.0033 & $\min ^{-1}$ & 0.07 & 0.10 & $\ldots$ & $\ldots$ \\
\hline$I_{u}$ & 0.000042 & {$[-]$} & 0.25 & 0.32 & $\ldots$ & $\ldots$ \\
\hline$r_{u}$ & 0.0010 & $\min ^{-1}$ & 1.16 & 2.03 & $\ldots$ & $\ldots$ \\
\hline$K_{u}$ & 0.05 & {$[-]$} & 0.69 & 0.76 & $\ldots$ & $\ldots$ \\
\hline$S_{u}$ & 0.00459 & $\mathrm{~mm}^{2} \min ^{-1}$ & 0.00 & 0.00 & $\ldots$ & $\ldots$ \\
\hline$T_{u}$ & 0.85 & {$[-]$} & 0.00 & 0.00 & $\cdots$ & $\cdots$ \\
\hline \multicolumn{7}{|c|}{$\begin{array}{l}\text { B. Two species dynamics following } \\
\text { uniform inoculation }{ }^{y}\end{array}$} \\
\hline$V_{b}$ & 0.0025 & $\min ^{-1}$ & -0.17 & -0.26 & 0.19 & 0.30 \\
\hline$I_{b}$ & 0.000018 & {$[-]$} & -0.38 & -0.49 & 0.43 & 0.55 \\
\hline$r_{b}$ & 0.0012 & $\min ^{-1}$ & -0.28 & -0.38 & 0.32 & 0.43 \\
\hline$K_{b}$ & 0.05 & {$[-]$} & 0.00 & 0.00 & 1.00 & 1.00 \\
\hline$S_{b}$ & 0.01398 & $\mathrm{~mm}^{2} \min ^{-1}$ & 0.00 & 0.00 & 0.00 & 0.00 \\
\hline$T_{b}$ & 0.85 & {$[-]$} & 0.00 & 0.00 & 0.00 & 0.00 \\
\hline$V_{u}$ & 0.0033 & $\min ^{-1}$ & 0.13 & 0.19 & -0.15 & -0.21 \\
\hline$I_{u}$ & 0.000042 & {$[-]$} & 0.47 & 0.57 & -0.53 & -0.64 \\
\hline$r_{u}$ & 0.0010 & $\min ^{-1}$ & 0.30 & 0.36 & -0.34 & -0.41 \\
\hline$K_{u}$ & 0.05 & {$[-]$} & 1.00 & 1.00 & 0.00 & 0.00 \\
\hline$S_{u}$ & 0.00459 & $\mathrm{~mm}^{2} \min ^{-1}$ & 0.00 & 0.00 & 0.00 & 0.00 \\
\hline$T_{u}$ & 0.85 & {$[-]$} & 0.00 & 0.00 & 0.00 & 0.00 \\
\hline \multicolumn{7}{|c|}{$\begin{array}{l}\text { C. Single species dynamics following } \\
\text { point inoculation }^{z}\end{array}$} \\
\hline$V_{b}$ & 0.0025 & $\min ^{-1}$ & $\ldots$ & $\ldots$ & 0.21 & 0.15 \\
\hline$I_{b}$ & 0.000018 & {$[-]$} & $\ldots$ & $\ldots$ & 0.36 & 0.37 \\
\hline$r_{b}$ & 0.0012 & $\min ^{-1}$ & $\ldots$ & $\ldots$ & 0.20 & 0.29 \\
\hline$K_{b}$ & 0.05 & {$[-]$} & $\ldots$ & $\ldots$ & 1.28 & 1.31 \\
\hline$S_{b}$ & 0.01398 & $\mathrm{~mm}^{2} \min ^{-1}$ & $\ldots$ & $\ldots$ & 0.00 & 0.00 \\
\hline$T_{b}$ & 0.85 & {$[-]$} & $\ldots$ & $\ldots$ & -8.09 & -7.82 \\
\hline$V_{u}$ & 0.0033 & $\min ^{-1}$ & 0.15 & 0.38 & $\ldots$ & $\ldots$ \\
\hline$I_{u}$ & 0.000042 & {$[-]$} & 0.61 & 0.77 & $\ldots$ & $\ldots$ \\
\hline$r_{u}$ & 0.0010 & $\min ^{-1}$ & 0.50 & 0.37 & $\ldots$ & $\ldots$ \\
\hline$K_{u}$ & 0.05 & {$[-]$} & 0.00 & 0.00 & $\ldots$ & $\ldots$ \\
\hline$S_{u}$ & 0.00459 & $\mathrm{~mm}^{2} \min ^{-1}$ & 1.59 & 1.28 & $\ldots$ & $\ldots$ \\
\hline$T_{u}$ & 0.85 & {$[-]$} & -7.32 & -8.83 & $\cdots$ & $\cdots$ \\
\hline \multicolumn{7}{|c|}{$\begin{array}{l}\text { D. Two species dynamics following } \\
\text { point inoculation }{ }^{z}\end{array}$} \\
\hline$V_{b}$ & 0.0025 & $\min ^{-1}$ & -0.06 & -0.07 & 0.01 & 0.01 \\
\hline$I_{b}$ & 0.000018 & {$[-]$} & -0.19 & -0.18 & 0.04 & 0.03 \\
\hline$r_{b}$ & 0.0012 & $\min ^{-1}$ & -0.20 & -0.22 & 0.04 & 0.05 \\
\hline$K_{b}$ & 0.05 & {$[-]$} & 0.00 & 0.00 & 0.00 & 0.00 \\
\hline$S_{b}$ & 0.01398 & $\mathrm{~mm}^{2} \min ^{-1}$ & -0.82 & -1.23 & 0.17 & 0.26 \\
\hline$T_{b}$ & 0.85 & {$[-]$} & 8.10 & 4.61 & -1.72 & -0.98 \\
\hline$V_{u}$ & 0.0033 & $\min ^{-1}$ & 0.03 & 0.08 & -0.01 & -0.01 \\
\hline$I_{u}$ & 0.000042 & {$[-]$} & 0.17 & 0.24 & -0.03 & -0.05 \\
\hline$r_{u}$ & 0.0010 & $\min ^{-1}$ & 0.29 & 0.31 & -0.06 & -0.07 \\
\hline$K_{u}$ & 0.05 & {$[-]$} & 0.00 & 0.00 & 0.00 & 0.00 \\
\hline$S_{u}$ & 0.00459 & $\mathrm{~mm}^{2} \min ^{-1}$ & 0.91 & 0.93 & -0.19 & -0.20 \\
\hline$T_{u}$ & 0.85 & {$[-]$} & -5.43 & -5.33 & 1.16 & 1.13 \\
\hline
\end{tabular}

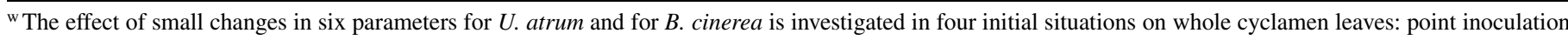
in monoculture (pattern equivalent to pattern 1, Fig. 2); point inoculation in mixed culture (pattern equivalent to pattern 11, Fig. 2); uniform inoculation in monoculture; and uniform inoculation in mixed culture. For each situation, a sensitive output variable was chosen: colony surface area, colonized leaf area, colonization level after $100 \mathrm{~h}$, and final colonization level, respectively. Parameters are the relative rate of local growth $\left(r_{b}, r_{u}\right)$, maximum colonization level $\left(K_{b}\right.$, $\left.K_{u}\right)$, spatial expansion coefficient $\left(S_{b}, S_{u}\right)$, spatial expansion threshold $\left(T_{b}, T_{u}\right)$, germination rate $\left(V_{b}, V_{u}\right)$, and initial mycelial density of a pre-established colony $\left(I_{b}, I_{u}\right)$. Relative sensitivity is calculated as the ratio of the percentage of change in the output variable to the percentage of change in the parameter.

${ }^{x}+$ Indicates an increased parameter value, whereas - indicates a decreased parameter value.

y Uniform inoculation with 10 conidia per grid cell.

${ }^{\mathrm{z}}$ Point inoculation with 10 conidia per inoculation point, 1 grid cell in size. 
the experimental results obtained using immuno-histological techniques. These errors indicate a large spatial variability of colonization in the substrate and an insufficient number of replicates in the experiments. Given the laboriousness of the immuno-histological techniques, a greater number of replicates was however not feasible. No significant differences between simulated and observed progress of colonization were found during the first approximately 4 days of fungal growth and competition in the substrate (Fig. 5). The variation in the experimental data however implies that even major discrepancies would not reach statistical significance. Hence, research into the patterns of spatial variability of fungal density in the substrate, and the causes for this variability, are necessary to make progress in the understanding of this aspect of fungal ecology.

Experimentally, fungal colonization at the leaf level was quantified using the sporulating leaf area corrected for intensity (SPLACI), a relative measure for sporulation (23). The simulation model calculates mycelial density in the substrate. Discrepancies between experimental and simulated head start experiments thus also underline quantitative differences between conidial reproduction and mycelial colonization. Reliable quantitative relationships between resource capture and reproductive output of both fungi (measured as SPLACI or otherwise) are not available but are urgently needed for a more accurate interpretation of these results. Competitive interactions, climatological factors, and nutritional factors are likely to affect these relationships (6).

Spatial expansion and competition were generally well described by the model (Fig. 2). Differences between experimental and simulated results were most likely caused by differences in experimental and simulated establishment of colonies following conidial point inoculation. Despite high average conidial densities, only $78 \%$ of the $U$. atrum point inoculations were successful, whereas B. cinerea point inoculations were $100 \%$ successful (experiment 2). Simulated colonies were successful by default. The process of establishment was not explicitly included in the model but was found to be relevant as a result of the simulations. Incorporation of establishment in the model will thus increase the practical applicability of the model.

$B$. cinerea has a considerable competitive advantage due to its greater radial growth rate. Spatial aspects of colony growth were however uninfluential when inoculations were uniform. For practical disease management, this implies that high $U$. atrum conidial densities, as uniformly distributed over the leaf as possible, will be most effective in colonizing newly available dead tissue and suppressing B. cinerea. Spray applications must then be timed as the phenology of dead tissues in the crop dictates.

Simulation results indicate that in spatially heterogeneous situations, spatial processes are key to the outcome of the competition. Simpler models based on radially growing circles (33) could be used in this situation, but for practical biocontrol purposes, a model as described here including both temporal and spatial resource competition is more versatile in its application and therefore more relevant to explore biological control options. The model may be used to identify acceptable levels of spatial heterogeneity regarding $U$. atrum conidial cover on foliage as related to disease pressure. Furthermore, it could be used to optimize spray applications with respect to choice of nozzle and dose rate. Away from the $B$. cinerea- $U$. atrum interaction, this model (with minor modifications) could be used to describe fungal interactions based on nutrient competition. Other fungal mechanisms of competition (e.g., antibiosis) could potentially be included but this would require major additions to the model.

Successful biological control of Botrytis spp. requires that the competitive interactions on dead substrates are won by $U$. atrum, such that Botrytis spp. loose their bridgeheads on these tissues. The models described in this paper may be indispensable to explore biocontrol options and optimize practical biological control strategies.

\section{ACKNOWLEDGMENTS}

This work was financially supported by the Technology Foundation (STW), GA, Utrecht, the Netherlands through project WBI44.3284. We thank the PCRaster team (Utrecht University) for technical support and stimulating discussions.

\section{LITERATURE CITED}

1. Boff, P., De Kraker, J., Van Bruggen, A. H. C., Gerlagh, M., and Köhl, J. 2001. Conidial Persistence and competitive ability of the antagonist Ulocladium atrum on strawberry leaves. Biocontrol Sci. Technol. 11:623-636.

2. Cooke, R. C., and Rayner, A. D. M. 1984. The Ecology of Saprotrophic Fungi. Longman, London.

3. De Wit, C. T. 1960. On competition. Versl. Landbouwkd. Onderz. (Agric. Res. Rep.) Wageningen 66:1-82.

4. Edelstein, L. 1982. The propagation of fungal colonies: A model for tissue growth. J. Theor. Biol. 98:679-701.

5. Edelstein, L., Hadar, Y., Chet, I., Henis, Y., and Segel, L. A. 1983. A model for fungal colony growth applied to Sclerotium rolfsii. J. Gen. Microbiol. 129:1873-1881.

6. Engelkes, C. A., Nuclo, R. L., and Fravel, D. R. 1997. Effect of carbon, nitrogen and $\mathrm{C}: \mathrm{N}$ ratio on growth, sporulation and biocontrol efficacy of Talaromyces flavus. Phytopathology 87:500-505.

7. Gerlagh, M., Amsing, J. J., Molhoek, W. M. L., Bosker-van Zessen, A. I., Lombaers-van der Plas, C. H., and Köhl, J. 2001. The effect of treatment with Ulocladium atrum on Botrytis cinerea-attack of geranium (Pelargonium zonale) stock plants and cuttings. Eur. J. Plant Pathol. 107:377-386.

8. Goudriaan, J. 1973. Dispersion in simulation models of population growth and salt movement in the soil. Neth. J. Agric. Sci. 21:269-281.

9. Goudriaan, J., and Van Roermund, H. J. W. 1993. Modelling of ageing, development, delays and dispersion. Pages 89-125 in: On Systems Analysis and Simulation of Ecological Processes. Vol. 1. P. A. Leffelaar, ed. Kluwer Academic Publishers, Dordrecht, the Netherlands.

10. Hau, B., and Kranz, J. 1978. Modellrechnungen zur Wirkung des Hyperparasiten Eudarluca caricis auf Rostepidemien. Z. Pflanzenkr. Pflanzenschutz 85:131-141.

11. Jarvis, W. R. 1977. Botryotinia and Botrytis Species: Taxonomy, Physiology and Pathology. Monogr. 15. Research Branch, Canada Department of Agriculture, Ottawa.

12. Jarvis, W. R. 1980. Epidemiology. Pages 219-250 in: The Biology of Botrytis. J. R. Coley-Smith, K. Verhoeff, and W. R. Jarvis, eds. Academic Press, London.

13. Kessel, G. J. T., de Haas, B. H., Lombaers-van der Plas, C. H., Meijer, E. M. J., Dewey, F. M., Goudriaan, J., van der Werf, W., and Köhl, J. 1999. Quantification of mycelium of Botrytis spp. and the antagonist Ulocladium atrum in necrotic leaf tissue of cyclamen and lily by fluorescence microscopy and image analysis. Phytopathology 89:868-876.

14. Kessel, G. J. T., de Haas, B. H., Lombaers-van der Plas, C. H., van den Ende, J. E., Pennock-Vos, M. G., van der Werf, W., and Köhl, J. 2001. Comparative analysis of the role of substrate specificity in biological control of Botrytis elliptica in lily and B. cinerea in cyclamen with Ulocladium atrum. Eur. J. Plant Pathol. 107:273-284.

15. Kessel, G. J. T., de Haas, B. H., van der Werf, W., and Köhl, J. 2002. Competitive substrate colonization by Botrytis cinerea and Ulocladium atrum in relation to biological control of Botrytis cinerea in cyclamen. Mycol. Res. 106:716-728.

16. Knudsen, G. R., and Hudler, G. W. 1987. Use of a computer simulation model to evaluate a plant disease biocontrol agent. Ecol. Model. 35:45-62.

17. Köhl, J., Bélanger, R., and Fokkema, N. J. 1997. Interaction of four antagonistic fungi with Botrytis aclada in dead onion leaves: A comparative microscopic and ultrastructural study. Phytopathology 87:634-642.

18. Köhl, J., Gerlagh, M., de Haas, B. H., and Krijger, M. C. 1998. Biological control of Botrytis cinerea in cyclamen with Ulocladium atrum and Gliocladium roseum under commercial growing conditions. Phytopathology 88:568-575.

19. Köhl, J., Gerlagh, M., and Grit, G. 2000. Biocontrol of Botrytis cinerea by Ulocladium atrum in different production systems of cyclamen. Plant Dis. 84:569-573.

20. Köhl, J., Lombaers-van der Plas, C. H., Molhoek, W. M. L., Kessel, G. J. T., and Goossen-van der Geijn, H. M. 1999. Competitive ability of the antagonist Ulocladium atrum at temperatures favourable for Botrytis spp. development. BioControl 44:329-346.

21. Köhl, J., and Molhoek, W. M. L. 2001. Effect of water potential on conidial germination and antagonism of Ulocladium atrum against Botrytis cinerea. Phytopathology 91:485-491.

22. Köhl, J., Molhoek, W. M. L., van der Plas, C. H., and Fokkema, N. J. 1995. Suppression of sporulation of Botrytis spp. as a valid biocontrol strategy. Eur. J. Plant Pathol. 101:251-259. 
23. Köhl, J., Molhoek, W. M. L., van der Plas, C. H., and Fokkema, N. J. 1995. Effect of Ulocladium atrum and other antagonists on sporulation of Botrytis cinerea on dead lily leaves exposed to field conditions. Phytopathology 85:393-401.

24. Köhl, J., van der Plas, C. H., Molhoek, W. M. L., and Fokkema, N. J. 1995. Effect of interrupted leaf wetness periods on suppression of sporulation of Botrytis allii and Botrytis cinerea by antagonists on dead onion leaves. Eur. J. Plant Pathol. 101:627-637.

25. Logan, J. A., Wollkind, D. J., Hoyt, S. C., and Tanigoshi, L. K. 1976. An analytic model for description of temperature dependent rate phenomena in arthropods. Environ. Entomol. 5:1133-1140.

26. Lotka, A. J. 1925. Elements of Physical Biology. Williams and Wilkins, Baltimore, MD.

27. Oude Voshaar, J. H. 1994. Statistiek voor Onderzoekers. Wageningen Press, Wageningen, the Netherlands.

28. Rabbinge, R., Ward, S. A., and van Laar, H. H. (eds.) 1989. Simulation and Systems Management in Crop Protection. Simulation Monographs 32. Pudoc Scientific Publishers, Wageningen.

29. Rayner, A. D. M., and Webber, J. F. 1984. Interspecific mycelial interactions-an overview. Pages 383-417 in: The Ecology and Physiology of Fungal Mycelium. D. H. Jennings and A. D. M. Rayner, eds. Cambridge University Press, Cambridge.

30. Rossing, W. A. H., Groot, J. J. R., and Van Roermund, H. J. W. 1989. Simulation of aphid damage in winter wheat: A case study. Pages 240-261 in: Simulation and Systems Management in Crop Protection. R. Rabbinge, S. A. Ward, and H. H. van Laar, eds. Simulation Monographs 32. Pudoc Scientific Publishers, Wageningen.
31. Schoene, P., and Köhl, J. 1999. Biologische Bekämpfung von Botrytis cinerea mit Ulocladium atrum in Reben und Cyclamen. Gesunde Pflanzen 51:81-85.

32. Trinci, A. P. J. 1984. Regulation of hyphal branching and hyphal orientation. Pages 23-52 in: The Ecology and Physiology of Fungal Mycelium. D. H. Jennings and A. D. M. Rayner, eds. Cambridge University Press, Cambridge.

33. Van Oijen, M. 1989. On the use of mathematical models from human epidemiology in breeding for resistance to polycyclic fungal leaf diseases of crops. Pages 26-37 in: Parental Line Breeding and Selection in Potato Breeding. K. M. Louwes, H. A. J. M. Toussaint, and L. M. W. Dellaert, eds. Pudoc Scientific Publishers, Wageningen.

34. Volterra, V. 1931. Variations and fluctuations of the number of individuals in animal species living together. Pages 409-448 in: Animal Ecology. R. N. Chapman, ed. McGraw-Hill, New York.

35. Wessels, J. G. H. 1988. A steady-state model for apical wall growth in fungi. Acta Bot. Neerl. 37:3-16.

36. Wessels, J. G. H., and Sietsema, J. H. 1984. Wall structure and growth in Schizophyllum commune. Pages 27-48 in: The Ecology and Physiology of the Fungal Mycelium. D. H. Jennings and A. D. M. Rayner, eds. Cambridge University Press, Cambridge.

37. Yunis, H., Shtienberg, D., Elad, Y., and Mahrer, Y. 1994. Qualitative approach for modelling outbreaks of grey mould epidemics in non-heated cucumber greenhouses. Crop Prot. 13:99-104.

38. Zegerman, M., Couteaudier, Y., Alabouvette, C., and Pavé, A. 1987. Modélisation du processus de compétition nutritive entre microorganismes: Application aux Fusarium. Agronomie 7:797-806. 